University of Wollongong

Research Online

Faculty of Engineering and Information

Faculty of Engineering and Information

Sciences - Papers: Part B

Sciences

2019

\title{
Mechanical Properties of Aluminium Metal Matrix Nanocomposites Manufactured by Assisted-Flake Powder Thixoforming Process
}

Saud Almotairy

University of Wollongong, King Saud University, smma660@uowmail.edu.au

Alireza Fadavi Boostani

Islamic Azad University, afb496@uowmail.edu.au

M Hassani

Islamic Azad University

Dongbin Wei

University of Technology Sydney, dwei@uow.edu.au

Zhengyi Jiang

University of Wollongong, jiang@uow.edu.au

Follow this and additional works at: https://ro.uow.edu.au/eispapers1

Part of the Engineering Commons, and the Science and Technology Studies Commons

Research Online is the open access institutional repository for the University of Wollongong. For further information contact the UOW Library: research-pubs@uow.edu.au 


\title{
Mechanical Properties of Aluminium Metal Matrix Nanocomposites Manufactured by Assisted-Flake Powder Thixoforming Process
}

\author{
Abstract \\ This study discusses the superior effect of thixoforming process on enhancing the tensile properties of \\ aluminium matrix composite produced using flake metallurgy route. The flake metallurgy process was \\ utilised to manufacture aluminium matrix composites followed by thixoforming process. Microstructural \\ investigations carried out using transmission electron microscope have shown the synergic effect of \\ thixoforming process on rendering uniform distribution of SiC nanoparticles associated with lower \\ porosity content. X-ray diffraction characterisations have revealed the promising effect of uniform \\ dispersion of $\mathrm{SiC}$ nanoparticles on restricting the grain growth of aluminium matrix within nanoscale \\ regime $(90 \mathrm{~nm})$ even at high semi-solid thixoforming temperatures $\left(575^{\circ} \mathrm{C}\right)$. The achieved results of \\ tensile tests have shown a profound effect of flake metallurgy of aluminium powder through dual speed \\ ball milling. These results are higher than those achieved by low speed and high speed even with higher \\ $\mathrm{SiC}$ content. This was attributed to the uniform confinement of SiC nanoparticles within the samples \\ produced using flake-assisted forming process compared to the ones manufactured using ball milling- \\ assisted processes.

\section{Disciplines} \\ Engineering | Science and Technology Studies

\section{Publication Details} \\ Almotairy, S. M., Fadavi Boostani, A., Hassani, M., Wei, D. \& Jiang, Z. Y. (2019). Mechanical Properties of \\ Aluminium Metal Matrix Nanocomposites Manufactured by Assisted-Flake Powder Thixoforming \\ Process. Metals and Materials International, Online First 1-9.
}




\title{
Mechanical Properties of Aluminium Metal Matrix Nanocomposites Manufactured by Assisted-Flake Powder Thixoforming Process
}

\author{
Saud M. Almotairy ${ }^{1,2, *}$, A. Fadavi Boostani ${ }^{3}$, M. Hassani ${ }^{4}$, D. Wei ${ }^{5}$, Z.Y. Jiang ${ }^{1, * *}$ \\ ${ }^{1}$ School of Mechanical, Materials, Mechatronic and Biomedical Engineering, University of Wollongong, NSW 2522, \\ Australia \\ ${ }^{2}$ Center of Excellence for Research in Engineering Materials (CEREM), King Saud University, P.O. Box 800, Riyadh \\ 11421, Saudi Arabia \\ ${ }^{3}$ Department of materials science and engineering, Majlesi Branch, Islamic Azad University, Majlesi, Isfahan, Iran \\ ${ }^{4}$ Department of Mechanical Engineering, Najafabad Branch, Islamic Azad University, Najafabad, Iran \\ ${ }^{5}$ School of Electrical, Mechanical and Mechatronic Systems, University of Technology, Sydney, NSW 2007, Australia
}

\begin{abstract}
This study discusses the superior effect of thixoforming process on enhancing the tensile properties of aluminium matrix composite produced using flake metallurgy route. The flake metallurgy process was utilised to manufacture aluminium matrix composites followed by thixoforming process. Microstructural investigations carried out using TEM have shown the synergic effect of thixoforming process on rendering uniform distribution of $\mathrm{SiC}$ nanoparticles associated with lower porosity content after implementation of thixoforming process. X-ray diffraction (XRD) characterisations have revealed the promising effect of uniform dispersion of SiC nanoparticles on restricting the grain growth of aluminium matrix within nanoscale regime (90 nm) even at high semi-solid thixoforming temperatures. The results achieved from implementation of tensile tests have shown a profound effect of flake metallurgy of aluminium powder manifested, through dual speed ball milling process in augmenting the yield strength
\end{abstract}

\section{Coresponding Authors:}

*Email address: smma660@uowmail.edu.au (Saud M. Almotairy)

${ }^{* *}$ Email address: jiang@uow.edu.au (Z. Y. Jiang) 
and tensile elongation of aluminium matrix nanocomposites, when compared to the ones manufactured by low speed ball milling and high speed ball milling processes even with higher $\mathrm{SiC}$ loading. This was attributed to the uniform confinement of SiC nanoparticles within the samples produced using flake-assisted forming process compared to the ones manufactured using ball milling-assisted processes.

Keywords: Thixoforming, Metal matrix composites, Mechanical properties, Powder metallurgy

\section{Introduction}

There is high demand for developing new materials to satisfy the advancement in engineering applications such as aerospace and vehicles [1]. This is attributed to the fact that a monolithic material generally cannot satisfy the necessities for having higher resistance to fatigue in many arduous purposes [2]. This, in turn, motivates researchers to manufacture composites with unique tensile properties, facilitating acquiring unprecedented performance for advanced metal matrix composites (MMCs). Incorporating ceramic reinforcements into the aluminium matrix can enhance the tensile strength, hardness, and both wear and corrosion resistances of the matrix $[3,4]$.

It has been approved that amalgamation of particulate reinforcements brings more advantageous compared to the composites produced by fiber reinforcements attributed to the fabrication cost and unique capability in optimising the isotropic microstructure and mechanical properties of the MMCs reinforced by particulate ceramic particles [5]. Based on this, there is a significant attention toward utilising SiC nanoparticles as reinforcement in MMCs, ascribed to the superior mechanical properties such as wear resistance [3] and mechanical properties especially at elevated temperatures [6] associated with lower manufacturing cost. The most critical aspect of this, however, is to control the distribution of SiC nanoparticles within metal matrix [7-9] and also to diminish the formation of the detrimental $\mathrm{Al}_{4} \mathrm{C}_{3}$ carbide at the interface of the $\mathrm{SiC}$ reinforcements and metal matrix [10]. 
Ball milling (BM) process is one of the promising routes to manufacture MMCs with enhanced mechanical properties associated with uniform distribution of nanoparticles within metal matrix [11]. This process outperforms other manufacturing methods such as casting due to its lower production temperatures, resulted in diminishing the interaction between the matrix and the reinforcement phases [12]. Although this process has a unique capability in conferring uniform distribution of nanoparticles to be dispersed within the matrix, well dispersion of nanoparticles is still a key challenge in developing manufacturing methods based on BM [13].

This has been resulted in developing new manufacturing route called flake powder metallurgy process to produce flake aluminium particles using ball milling process [14] and slurry blending the as milled aluminium flakes as starting materials [15-17].

This new flake metallurgy encompasses dual-speed ball milling process, benefitting from lowspeed and high-speed ball milling (LSBM and HSBM) processes. It has been shown that reduction in ball milling speed can bring about more uniform dispersion of nanoreinforcement such as carbon nanotubes (CNTs) within aluminium flakes [18, 19]. Additionally, it has been made clear that aluminium flakes produced using ball milling process can represent flatten surfaces and large specific surface areas, which are compatible to accommodate the uniform dispersion of nanoreinforcement, i.e. CNTs, within aluminium particles [14].

This study presents a new model for microstructural evolution of aluminium particles to be transferred to the layer by implementing the new process called dual speed ball milling (DSBM) process, including the combination of low-speed and high-speed milling speed, and changing the milling time during ball milling process [20]. To this end, this study aims at developing flake powder metallurgy route to produce the aluminium matrix nanocomposites with uniform distribution of SiC nanoparticles associated with implementation of thixoforming process to diminish the porosity content of the produced composites compared to those produced by other process such as hot isostatic pressing that we studied before [Ref?].

This study also demonstrates the microstructure analysis conducted using TEM to understand the relationships between the process parameters and the microstructures after the thixoforming 
process. Moreover, the effect of thixoforming process on the crystallite size of the samples is presented by implementing the X- Ray diffraction (XRD) tests on the bulk samples after thixoforming process. The mechanical properties of the thixoformed samples then are investigated using the tensile and hardness tests and results are analysed based on the microstructural and XRD investigations.

\section{Experimental Procedure}

The nanocomposite powder mixture was milled at different milling times of 1-10 h by a planetary ball mill at low-speed (200 RPM) ball milling (LSBM) and high-speed (600 RPM) ball milling (HSBM) with the aim of achieving homogeneous and uniform distribution of reinforcement particles within the matrix.

Table 1 Nomination system of the powder and bulk specimens produced in this study associated with applied changes in manufacturing parameters.

\begin{tabular}{ccccc}
\hline $\begin{array}{c}\text { Brief } \\
\text { name }\end{array}$ & $\begin{array}{c}\text { SiC } \\
\text { (Vol. \%) }\end{array}$ & $\begin{array}{c}\text { Stearic Acid } \\
\text { (Vol. \%) }\end{array}$ & $\begin{array}{c}\text { Ball milling } \\
\text { speed (RPM) }\end{array}$ & $\begin{array}{c}\text { Ball milling } \\
\text { Time (h) }\end{array}$ \\
\hline LSBM & $1,3,6$ & $1,2,3$ & 200 & $1-10$ \\
\hline & & & & $9(200)+1(600)$ \\
& & & & $8(200)+2(600)$ \\
& & & & $7(200)+3(600)$ \\
DSBM & $1,3,6$ & $1,2,3$ & $200+600$ & $6(200)+4(600)$ \\
& & & & $5(200)+5(600)$ \\
& & & & $3(200)+6(600)$ \\
& & & & $2(200)+8(600)$ \\
& & & & $1(200)+9(600)$ \\
HSBM & $1,3,6$ & $1,2,3$ & 600 & $10(600)$ \\
\hline
\end{tabular}

Additionally, as it can be seen from Table 1, a combination of low-speed (200 RPM) ball milling (LSBM) and high-speed (600 RPM) ball milling (HSBM) was also employed as a dualspeed ball milling (DSBM) process to investigate the effect of changing the ball milling time and speed together on the mechanical properties of the produced composites. This process was utilised to take the advantage of LSBM process to make a uniform dispersion of SiC nanoparticles within aluminium flakes followed by high-speed ball milling (HSBM) to achieve a good bonding between the produced flakes. Moreover, the high-speed ball milling was 
chosen to produce nanocomposites because of its capability to mix in a short time with a smaller volume (capability of better controlling) to mix of the reinforcement particles into the aluminium alloy matrix and create a nanostructure matrix. In this process, the ball milling process was first initiated at low-speed milling conditions (200 RPM) and then followed by milling at higher speed (600 RPM) with total milling time of $10 \mathrm{~h}$.

Table 1 demonstrates a nomination system used to identify different specimens in the rest of this study. It has been approved before that the formation of aluminium flakes can enhance the confinement of nanoparticles within metal matrix during manufacturing process [14], however, the level by which this engulfment of nanoparticles was achieved is affected by the post processing treatment applied on the produced powder.

The effects of thixoforming process on the microstructure and mechanical properties of aluminium matrix composites produced using powder metallurgy route were analysed in the study. Prepared composites powder were subjected to thixoforming process at different temperatures of 555,565 and $575^{\circ} \mathrm{C}$ corresponding to the liquid fraction of $0.1,0.25$ and 0.4 , respectively, for the holding time of $30 \mathrm{~min}$ with a heating rate of $35{ }^{\circ} \mathrm{C} / \mathrm{min}$. The thixoforming process was accomplished under the fixed thixoforming pressure of $150 \mathrm{MPa}$ in a chamber of uniaxial press protected by high purity (99.99\%) argon gas.

\section{Results and Discussions}

\subsection{Optimisation}

In order to select the optimised ball milling conditions such as milling time, milling speed, SiC and stearic acid volume content to achieve higher tensile properties, especially yield strength, after thixoforming process, aluminium powders, with different percentages of SiC and stearic acid volume content under different milling speeds and times, were ball milled according to Table 1, then were thixoformed.

Tensile tests were conducted on the thixoformed samples and the results of these tests were investigated. It has been found that TDSBM samples, manufactured using thixoforming of the 
powders prepared by a combination of low-speed (200 RPM) ball milling (LSBM) and highspeed (600 RPM) ball milling (HSBM) processes, have shown more enhancements in the yield strength compared to other samples.

In fact, the TLSBM samples, representing the samples manufactured using thixoforming of the powders prepared by a low-speed (200 RPM) ball milling (LSBM) process, and THSBM samples, showing the samples manufactured using thixoforming of the powders prepared by a high-speed (600 RPM) ball milling (HSBM) process, suffer from lower yield strengths.

The samples with high yield strength of each group were selected as best nominees to be investigated in the rest of this study. These samples with higher yield strength were called as TLSBM (270 MPa), TDSBM (400 MPa MPa), and THSBM (295 MPa) samples in the rest of this study. Table 2 shows the highest tensile achieved for each group associated with the processing parameters.

Table 2 Highest tensile achieved for each group associated with the processing parameters

\begin{tabular}{cccccc}
\hline samples & $\begin{array}{c}\text { SiC } \\
\text { (Vol. \%) }\end{array}$ & $\begin{array}{c}\text { Stearic acid } \\
\text { (Vol. \%) }\end{array}$ & $\begin{array}{c}\text { Ball milling } \\
\text { speed (RPM) }\end{array}$ & $\begin{array}{c}\text { Ball milling } \\
\text { Time (h) }\end{array}$ & $\begin{array}{c}\text { Tensile } \\
\text { MPa }\end{array}$ \\
\hline TLSBM & 1 & 2 & 200 & 2 & 270 \\
\hline TDSBM & 3 & 2 & $200+600$ & $8(200)+2(600)$ & 400 \\
\hline THSBM & 6 & 2 & 600 & 2 & 295 \\
\hline
\end{tabular}

For example, TDSBM sample with SiC content of 3 Vol. \% contains 2 Vol. \% stearic acid and represents more yield strength (400 $\mathrm{MPa}$ ) compared to other thixoforming samples. TLSBM and THSBM samples, in contrast, have lower yield strength. Regarding THSBM samples, this lower yield strength can be related to the higher volume content of SiC nanoparticles in this sample, augmenting the propensity of these nanoparticles to agglomerate compared to TLSBM and TDSBM samples with lower SiC contents (i.e. 1 and 3 Vol.\%). The lower yield strength of the TLSBM sample, however, can be attributed to the nonuniform distribution of nanoparticles in this sample. These potential reasons for lower yield strength of the TLSBM and THSBM samples will be further confirmed in the next sections dealing mainly with microstructural and mechanical analysis of the powder and bulk thixoformed samples. 
It can be concluded that there is an optimum value (2 Vol.\%) for the volume percentage of the stearic acid in the all thixoforming samples, resulted in more enhancements in the yield strength compared to other samples. In fact, this is the critical stearic acid content [21, 22] hindering the agglomeration of aluminium particles during the milling process by diminishing the coldwelding of aluminium particles. In the other words, lower values of stearic acid cannot effectively diminish the agglomeration process of aluminium particles [23], but the higher values (3 Vol.\%) can produce the detrimental aluminium carbide $\left(\mathrm{Al}_{4} \mathrm{C}_{3}\right)$ [24], deteriorating the tensile properties.

\subsection{Microstructural Analysis}

The microstructure of composites powder that are ball milled for $2 \mathrm{~h}$ are presented in Fig. 1. The reinforcement contents in these samples are 1 vol. \% in (LSBM), 3 vol. \% in (DSBM) and 6 vol. \% in (HSBM) with SiC nanoparticles size of average $45 \mathrm{~nm}$.
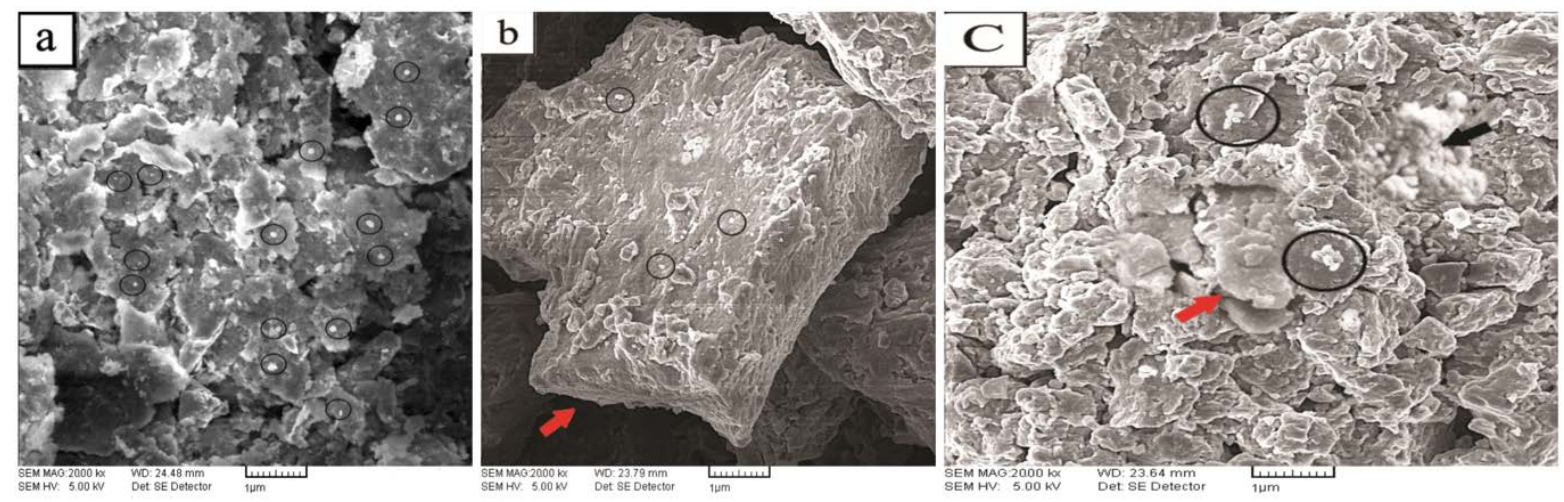

Fig. 1 FE-SEM micrograph of (a)LSBM, (b)DSBM, and (c)HSBM samples.

It can be seen from this figure that the evolution of particles' morphologies in LSBM and HSBM samples are mostly same with large aluminium particles containing agglomerated SiC nanoparticles. The difference between LSBM and HSBM samples is related to the tendency of $\mathrm{SiC}$ nanoparticles to be agglomerated in HSBM sample, due to rapid cold welding without achieving uniform distribution assisted by higher $\mathrm{SiC}$ content in this sample. As shown in Fig. 1(c) by black circles, there is clear evidence of formation of SiC nanoparticles with clustered 
morphology. Furthermore, there is a large cluster formed as shown by the black arrow in Fig. 1(c), which is not seen in other samples.

As can be seen from Fig. 1 (b), DSBM sample has been formed in a flake shape with SiC nanoparticles established on the top of these flakes with uniform distribution, as shown by black circles approving the lower possibility of agglomerating $\mathrm{SiC}$ nanoparticles in this sample compared to other samples. These results validate the fact that ball milling of aluminium matrix at early time can be achieved by the shearing forces, though the effectiveness of this shearing force to produce aluminium flakes considerably depends on the content of $\mathrm{SiC}$ nanoparticles. In fact, it is suggested that there is a critical amount of SiC nanoparticles, i.e. 3 Vol. \%, which can accelerate the shearing of aluminium particles to form flake morphology during ball milling process. However, the effect of this critical amount cannot be isolated from other parameters. In fact, it is correlated with the employment of dual speed ball milling. This is because shifting to higher speed results in stronger ball collision accelerating cold welding of $\mathrm{Al}$ flakes and leading to more dispersion of the previous uniformly distributed $\mathrm{SiC}$ nanoparticles with better bonding.

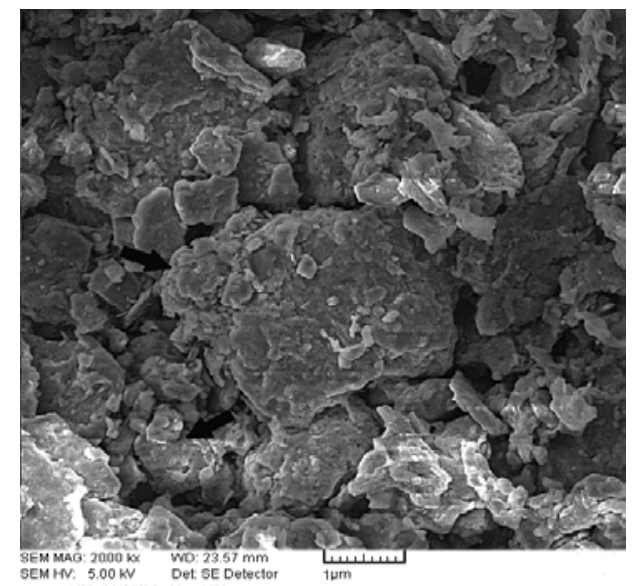

Fig. 2 FE-SEM micrograph of DSBM powder sample ball milled for $6 \mathrm{~h}$ at high speed regime.

Nevertheless, prolonged ball milling of DSBM sample in the milling times longer than the optimum time of $2 \mathrm{~h}$ after shifting to high-speed regime can result in formation of big aluminium particles with agglomerated morphology, as shown by black arrows in Fig. 2. This 
is due to the fact that after a length of time during HSBM, detaching of SiC nanoparticles from $\mathrm{Al}$ matrix could take place leading to re-agglomeration of these $\mathrm{SiC}$ nanoparticles.

From microstructural point of view it is good idea to have insight into the effect of thixoforming on the microstructural properties of the produced bulk composites, microstructure of the thixoformed samples was investigated using TEM as shown in Fig. 3.

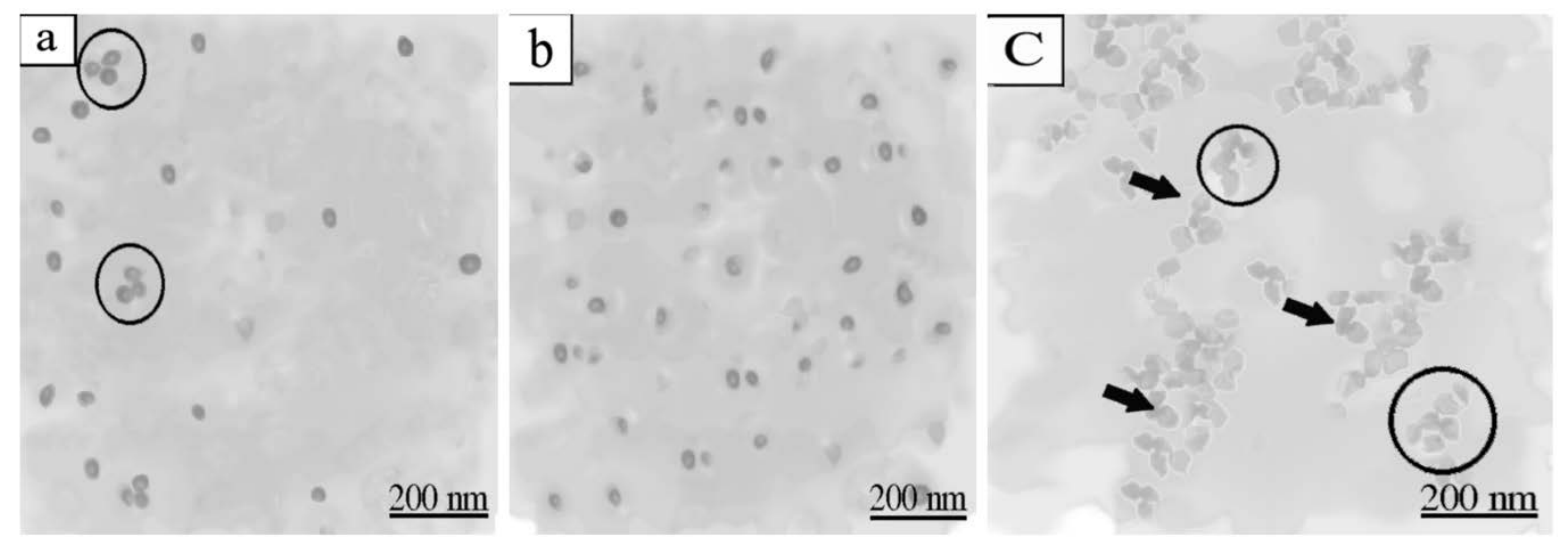

Fig. 3 TEM micrograph of (a) TLSBM, (b) TDSBM, (c) THSBM samples thixoformed at $565^{\circ} \mathrm{C}$.

It can be seen from Fig. 3 (b), there is no any evidence for formation of agglomerated SiC nanoparticles in TDSBM samples. As shown in Fig. 3 (b), the microstructure of the TDSBM sample is different from the ones seen for TLSBM and THSBM samples. It is apparent that the microstructure of the TDSBM sample contains uniform distribution of SiC nanoparticles, nevertheless, these particles are susceptible to be agglomerated in the TLSBM and THSBM samples.

The important discrepancy between the agglomerated particles in the THSBM and TLSBM samples is related to the formation of SiC nanoparticles with integrated structure in the THSBM sample, as shown by black arrows in Fig. 3 (c), which is different from the cluster morphology of SiC nanoparticles in TLSBM sample. 


\subsection{Process Mechanism}

Based on the microstructural analysis of the different composites in powder form and after thixoforming, a process mechanism has been suggested and presented in Fig. 4. This suggestion is an attempt to explain two different routes. Firstly, it explains the ball milling-assisted thixoforming (BAT) process including the application of thixoforming on the aluminium matrix composite reinforced by SiC nanoparticles and produced by the ball milling process. As shown in Fig. 4 (a), at the first step aluminium particles are subjected to the circulation of liquid flow as a result of pressure applied during reheating process in thixoforming process. As the thixoforming process progresses as shown in Fig. 4 (b), the aluminium particles are closed together while the $\mathrm{SiC}$ nanoparticles are tended to agglomerate together as a result of circulation of liquid between aluminium particles. Finally, the aluminium particles are forced together, resulted in production of aluminium matrix nanocomposites with agglomerated SiC nanoparticles, as shown in Fig. 4 (d).

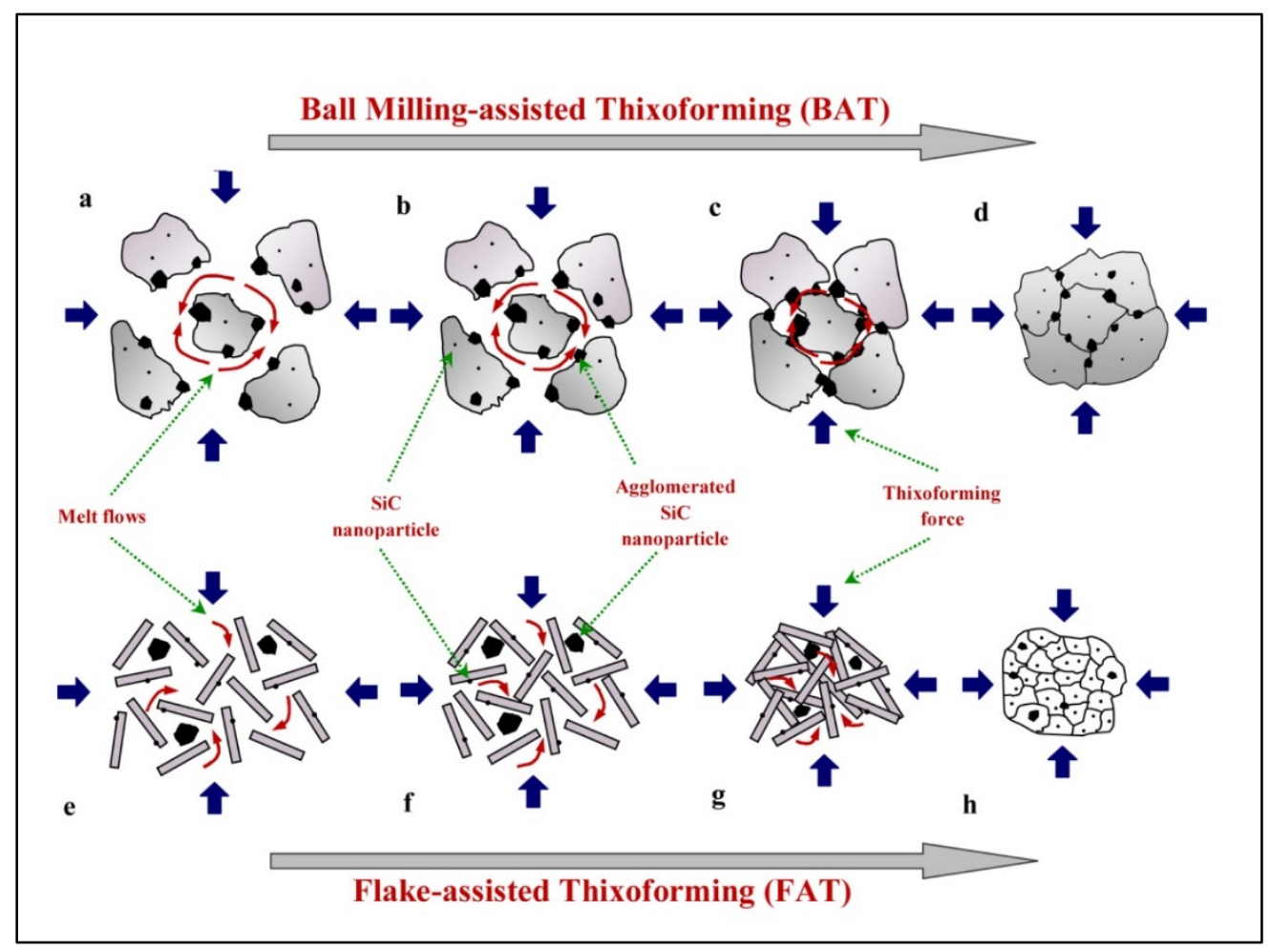

Fig. 4 Schematic picture of various stages of ball milling-assisted thixoforming (BAT) and flake-assisted thixoforming (FAT) process. 
The second route represents the flake-assisted thixoforming (FAT) process, including the implementation of thixoforming process on the aluminium matrix composite reinforced by SiC nanoparticles and produced by the flake powder metallurgy process, which stated as shown in Fig. 4 (e). At the first step in the FAT process, aluminium flakes with uniform distribution of SiC nanoparticles are subjected to the circulation of liquid aluminium (red arrows in Fig. 4 (e)). Then in the next step, as shown in Fig. 4 (f), the aluminium flakes are closed together by application of thixoforming pressure. By progressing the FAT process, as shown in Fig. 4 (g), aluminium flakes are going to pack together with uniform distribution of SiC nanoparticles entrapped between aluminium flakes and some agglomerated SiC nanoparticles.

\subsection{Crystallite Size}

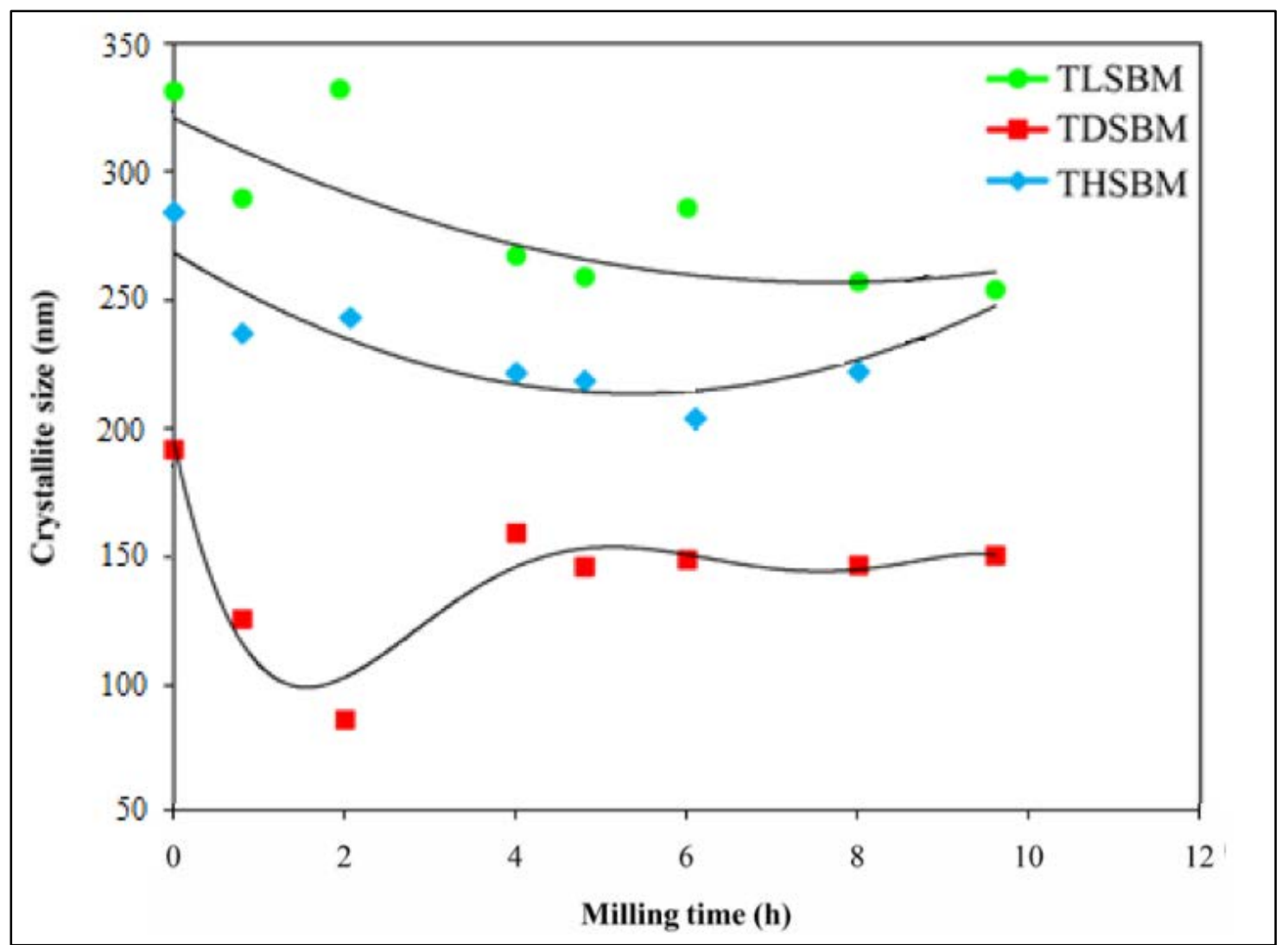

Fig. 5 Effect of thixoforming process on the crystallite size of samples ball milled at different ball milling times and thixoformed at $565^{\circ} \mathrm{C}$. 
Fig. 5 represents changes of crystallite size for samples thixoformed at $565^{\circ} \mathrm{C}$, including TLSBM, TDSBM and THSBM samples, as a function of the milling times. Fig. 5 shows results achieved from investigation of the XRD analysis performed on the thixoformed samples at $565^{\circ} \mathrm{C}$ for different milling times. Fig. 5 demonstrates the effectiveness of flake-assisted thixoforming (FAT) process on restricting the growth of the crystallite size of aluminium matrix in the nano scale regime compared to other samples such as TLSBM and THSBM samples, demonstrating the severe growth of crystallite for all samples ball milled at different milling times.

As shown in Fig. 5, thixoforming process has brought about an enhancement in crystallite size of samples, but the degree of this enhancement is more considerable in TLSBM and THSBM samples compared with other TDSBM samples. A subtle investigation of Fig. 5 shows that the minimum growth of crystallite size is achieved for the thixoformed samples ball milled at $2 \mathrm{~h}$ which means it was ball milled for $8 \mathrm{~h}$ at low speed and then for $2 \mathrm{~h}$ at a high speed. In contrast other samples ball milled with lower speed (TLSBM) and high speed (THSBM) represents higher crystallite sizes, as depicted by the green and blue squares in Fig. 5. This can be related to the distortion brought out by ball milling for the aluminium flakes for longer ball milling times, deteriorating the capability of these flakes for engulfment of the SiC nanoparticles. This fact has been shown in Fig. 2 for the aluminium flakes ball milled for 6 h, demonstrating the formation of agglomerated SiC nanoparticles for extended milling times.

TLSBM and THSBM samples, in contrast, represent crystallite size bigger than $210 \mathrm{~nm}$, indicating the existence of extensive grain growth in these samples during thixoforming process. This can be explained based on the formation of agglomerated SiC nanoparticles in these samples during ball milling process, as shown in Fig. 2.

\subsection{Relative Density}

To reveal the effect of temperature utilised for thixoforming process on the density of produced composites, the relative density of thixoformed samples at different semi-solid temperatures are presented in Fig. 6. This figure surprisingly shows that by increasing the thixoforming 
temperature the density of samples reduces in thixoformed samples. The degree of this reduction in the density of the samples, however, is more sever in the THSBM samples compared to other samples, as shown in Fig. 6. This is related to the fact that the higher thixoforming temperature $\left(575{ }^{\circ} \mathrm{C}\right)$ is resulted in enhancing the liquid fraction of the thixoformed samples (0.4), thereby increasing the possibility for agglomeration of $\mathrm{SiC}$ nanoparticles.

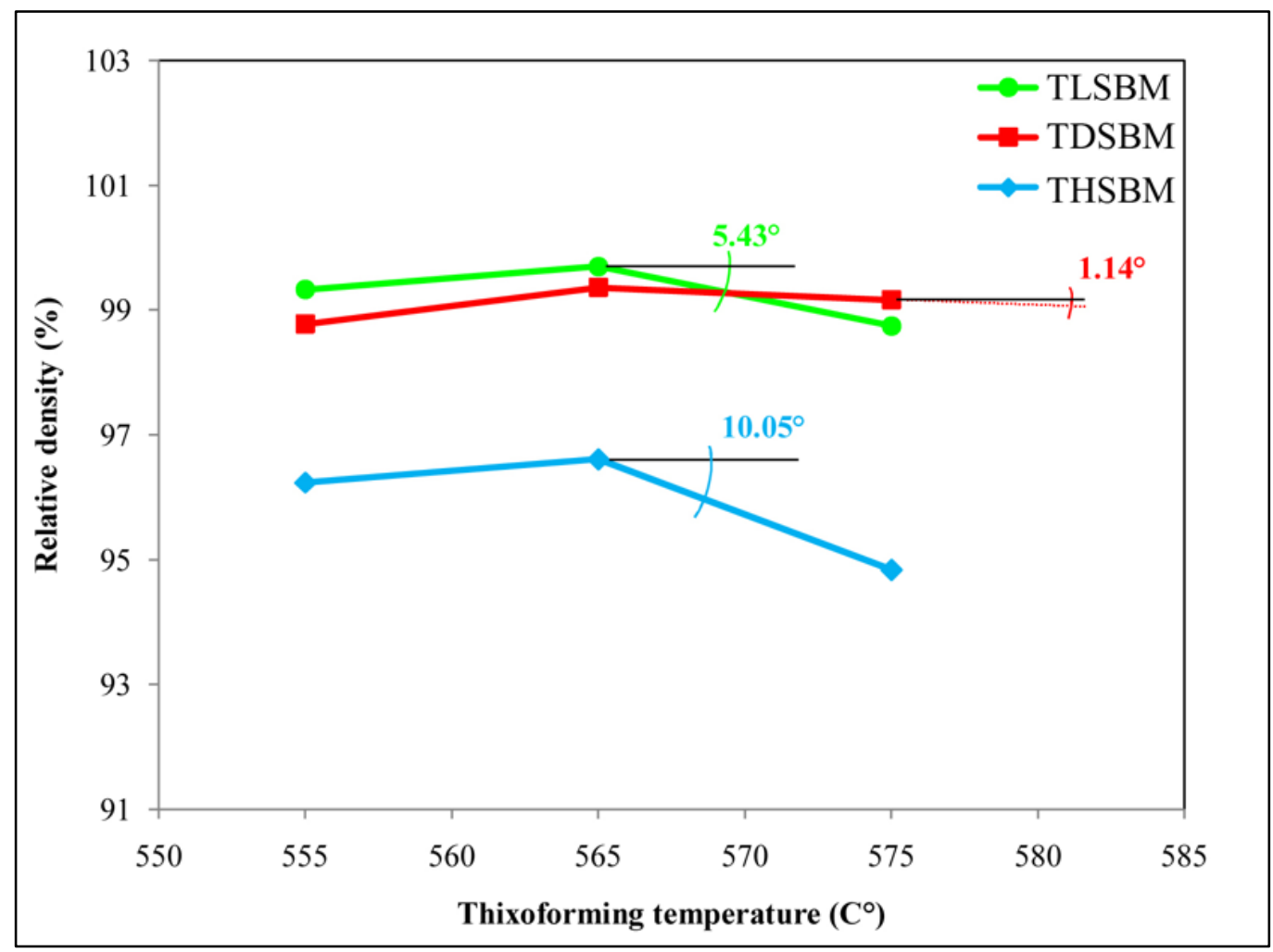

Fig. 6 Effect of content of SiC nanoparticles and thixoforming temperatures on the relative density of the samples thixoformed at different thixoforming temperatures.

This, in turn, enhances the porosity content of the thixoformed samples deformed at high temperatures $\left(575^{\circ} \mathrm{C}\right)$ compared to those thixoformed at lower temperatures such as 555 and $565{ }^{\circ} \mathrm{C}$. Additionally, as shown in Fig. 6, thixoformed samples containing higher volume percentages of SiC nanoparticles (THSBM) demonstrate a lower density compared to TLSBM sample. This is ascribed to the higher propensity of entrapment of porosity between agglomerated $\mathrm{SiC}$ nanoparticles which are more predominant in THSBM sample, as demonstrated in Fig. 3. 
The relative density of the TDSBM sample, however, is close to the TLSBM sample, as shown in Fig. 6. This can be explained based on the uniform distribution of $\mathrm{SiC}$ nanoparticles in this sample due to implementation of flake metallurgy process. In fact, SiC nanoparticles in TDSBM sample are distributed uniformly between aluminium flakes which resulted in diminishing the possibility for sever agglomeration during thixoforming process especially at lower temperatures.

\subsection{Mechanical Properties}

Fig. 7 represents the tensile behavior of the thixoformed samples to determine their yield stress (YS), tensile strength (UTS), and total elongation (\%). As shown in Fig. 7, the tensile strength of the TDSBM sample (570 MPa) is superior to the ones reported for TLSBM and THSBM samples registering the UTS values of about $350 \mathrm{MPa}$ and $395 \mathrm{MPa}$, respectively.

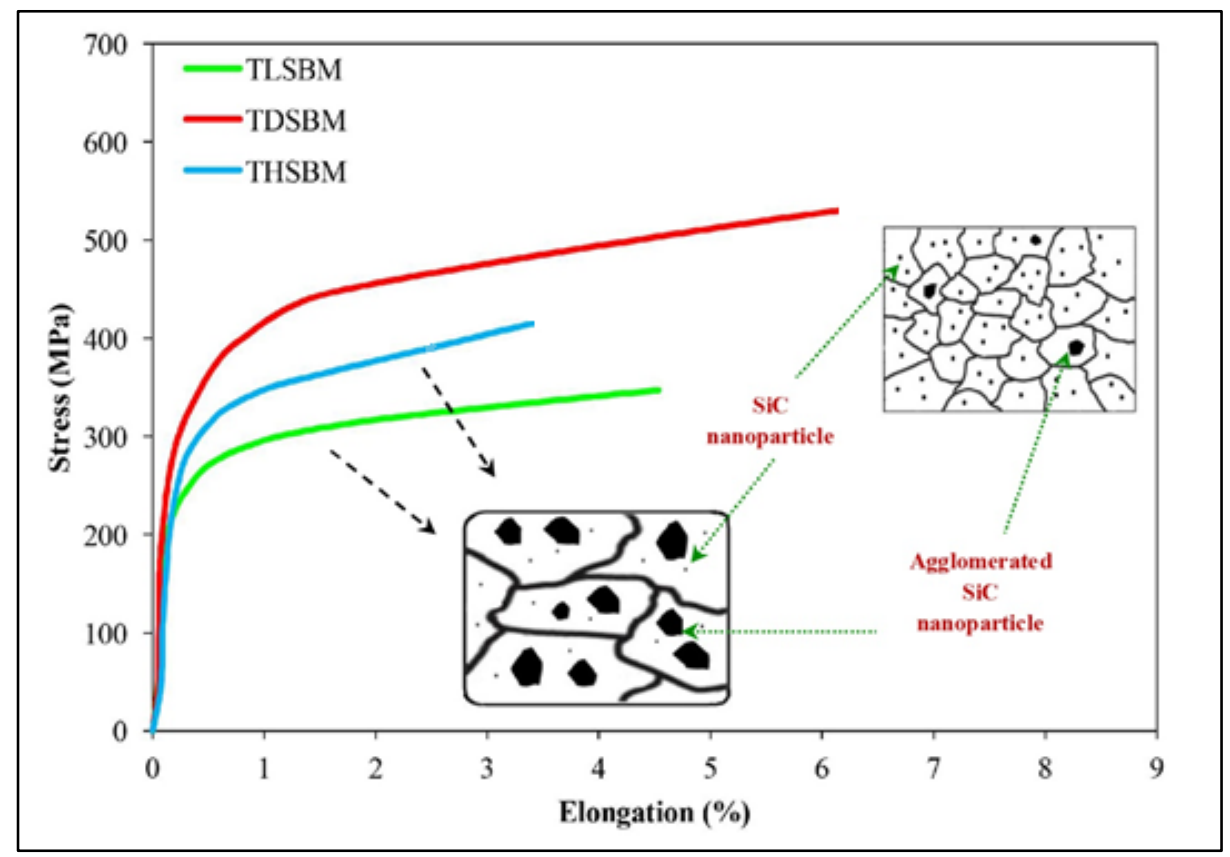

Fig. 7 Stress-strain curve of TLSBM, TDSBM and THSBM samples thixoformed at $565^{\circ} \mathrm{C}$ accompanied with schematic illustration of their microstructures.

This higher UTS value reported for TDSBM sample is attributed to the effect of the uniform distribution of $\mathrm{SiC}$ nanoparticles within the aluminium matrix in this sample, as shown in Fig. 
3, and lower porosity content of this sample compared to THSBM sample. Regarding uniform dispersion of SiC nanoparticles in TDSBM sample, it can have a beneficial effect on diminishing the grain growth of the aluminium matrix during reheating process, resulted in production of grain with crystallite size of about $90 \mathrm{~nm}$. As shown in Fig. 3, TLSBM and THSBM samples, in contrast, suffer from agglomeration of SiC nanoparticles within aluminium matrix, diminishing the effectiveness of $\mathrm{SiC}$ nanoparticles in controlling the grain growth within the nanoscale regime, as represented in Fig. 3.

It should be considered that irrespective of a higher relative density of TLSBM sample in respect to TDSBM sample, however, the ductility of the TDSBM sample (6.2\%) is more significant compared to the THSBM sample (3.6\%), as shown in Fig. 7. This can be correlated to the uniform distribution of SiC nanoparticles in the TDSBM samples, as shown in Fig. 3 (b). TLSBM sample, however, contains some agglomerated SiC nanoparticles, diminishing the amount of the $\mathrm{SiC}$ nanoparticles in the microstructure to control the grain growth of aluminium matrix during reheating process in the thixoforming process. This, in turn, stimulates the agglomeration of $\mathrm{SiC}$ nanoparticles at the grain boundaries, as depicted in the schematic picture of Fig. 4, facilitating low energy path for crack propagation through grain boundaries. This, in turn, results in diminishing the ductility of the TLSBM sample, as shown in Fig. 7.

Fig. 8 demonstrates the hardness of thixoformed samples accompanied by pure aluminium thixoformed under the same condition. It can be seen from Fig. 8, although the unreinforced aluminium has been thixoformed at the same conditions that other $\mathrm{SiC}$ reinforced aluminium samples, it represents significantly diminished hardness compared to other thixoformed composites.

This improved hardness of thixoformed samples can be related to the considerable diminishing in the crystallite size of thixoformed composites especially TDSBM sample even at high thixoforming temperature like $565^{\circ} \mathrm{C}$ used in this study. As shown in Fig. 8, SiC nanoparticles incorporated within aluminium matrix can augment the hardness of the produced composites significantly. This can be pertinent to the enhanced density of dislocations generated within aluminium matrix as a result of these particles. As can be seen in Fig. 8, the hardness of TLSBM sample is around $100 \mathrm{HV}$ which is lower than THSBM sample, demonstrating hardness value 
around $118 \mathrm{HV}$, which is in an agreement with the fact that adding the SiC content of the composites can enhance the hardness.

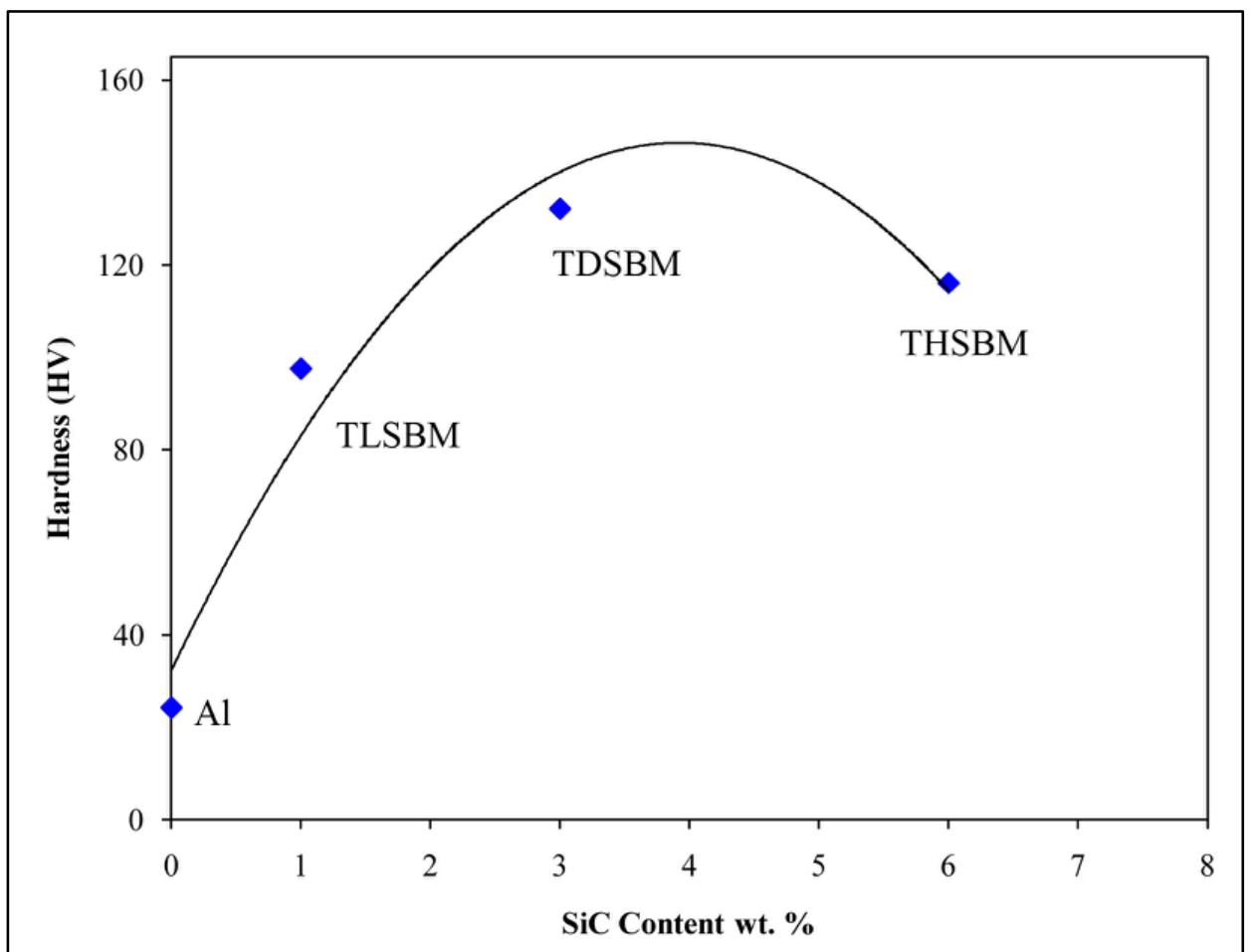

Fig. 8 Results of the Vickers hardness test conducted on TLSBM, TDSBM and THSBM samples thixoformed at $565^{\circ} \mathrm{C}$.

The hardness of the TDSBM, however, outperforms the ones reported for other samples, which is not in an agreement with the fact that adding the $\mathrm{SiC}$ content of the composites can enhance the hardness. This can be ascribed to the fact that uniform distribution of SiC nanoparticles plays more profound role in enhancing the hardness of the produced composites compared to the enhancing the SiC content of the composites. This, in turn, is related to the enhanced dislocation density of the TDSBM sample compared to the THSBM sample due to the lower crystallite size of this sample compared to the THSBM sample, as shown in Fig. 8.

\section{Conclusions}

This study demonstrates the effectiveness of thixoforming process on enhancing the relative density (99.2 \%) of the powder composites manufactured using flake powder metallurgy. TEM 
investigations carried out on the thixoformed samples have shown that the uniform distribution of $\mathrm{SiC}$ nanoparticles achieved from the flake powder metallurgy process has not been changed significantly during thixoforming process. A thixoforming model devised in this study has attributed this to the flake morphology of aluminium particles, making it possible to confine the nanoparticles during milling and subsequent thixoforming process. This has also been supported by the semi-solid nature of thixoforming process, diminishing the severe movement of nanoparticles due to the high viscosity of the liquid trapped between the flakes during thixoforming.

XRD investigations have also represented that profound capacity of the flake powder metallurgy resulted in uniform distribution of $\mathrm{SiC}$ nanoparticles, so that these nanoparticles impose considerable restriction on the grain growth of the thixoformed samples. In fact, the crystallite size of the thixoformed samples produced using the flake powder metallurgy route has been limited to the values lower than $200 \mathrm{~nm}$ compared to the $500 \mathrm{~nm}$ seen in the hot isostatically pressed samples in our previous study.

In additional, the diminished agglomeration of $\mathrm{SiC}$ nanoparticles in thixoformed samples resulted in surprising capacity of thixoforming process on diminishing the porosity content along with a unique behavior in restricting the grain growth. Tensile test results have shown that the thixoformed samples can register about $32 \%$ and $26 \%$ enhancement in the tensile strength and elongation of the thixoformed samples respectively, comparing to the ones produced for the hot isostatically presses composites, respectively. Results achieved from the microhardness tests conducted on the samples have also shown that thixoformed samples with uniform distribution of SiC nanoparticles can enhance the microhardness by about 364\%, when comparing to the unreinforced aluminium thixoformed in the same conditions.

\section{Acknowledgment}

The first author extends his gratefulness for receiving scholarship as part of The Custodian of the two Holy Mosques' Overseas Scholarship Program.

\section{References}


[1] N. Selvakumar, B. Gnanasundarajayaraja, and P. Rajeshkumar, "Enhancing the Properties of Al-WC Nanocomposites Using Liquid Metallurgy," Experimental Techniques, vol. 40, pp. 129-135, Feb. 2016.

[2] N. Chawla and Y. L. Shen, "Mechanical Behavior of Particle Reinforced Metal Matrix Composites," Advanced Engineering Materials, vol. 3, pp. 357-370, May. 2001.

[3] M. Karbalaei Akbari, S. Rajabi, K. Shirvanimoghaddam, and H. R. Baharvandi, "Wear and friction behavior of nanosized TiB2 and TiO2 particle-reinforced casting A356 aluminum nanocomposites: A comparative study focusing on particle capture in matrix," Journal of Composite Materials, vol. 49, pp. 3665-3681, Dec. 2015.

[4] M. Karbalaei Akbari, H. R. Baharvandi, and K. Shirvanimoghaddam, "Tensile and fracture behavior of nano/micro TiB2 particle reinforced casting A356 aluminum alloy composites," Materials \& Design (1980-2015), vol. 66, pp. 150-161, Feb. 2015.

[5] S. K. Thandalam, S. Ramanathan, and S. Sundarrajan, "Synthesis, microstructural and mechanical properties of ex situ zircon particles ( $\mathrm{ZrSiO} 4)$ reinforced Metal Matrix Composites (MMCs): a review," Journal of Materials Research and Technology, vol. 4, pp. 333-347, July. 2015.

[6] J. J. Grácio, C. R. Picu, G. Vincze, N. Mathew, T. Schubert, A. Lopes, et al., "Mechanical Behavior of Al-SiC Nanocomposites Produced by Ball Milling and Spark Plasma Sintering," Metallurgical and Materials Transactions A, vol. 44, pp. 5259-5269, Nov. 2013.

[7] J. Hashim, L. Looney, and M. S. J. Hashmi, "Particle distribution in cast metal matrix composites_-Part I," Journal of Materials Processing Technology, vol. 123, pp. 251257, Apr. 2002.

[8] J. Hashim, L. Looney, and M. S. J. Hashmi, "Particle distribution in cast metal matrix composites-Part II," Journal of Materials Processing Technology, vol. 123, pp. 258263, Apr. 2002.

[9] I. S. El-Mahallawi, Y. Shash, K. Eigenfeld, T. S. Mahmoud, R. M. Ragaie, A. Y. Shash, et al., "Influence of nanodispersions on strength-ductility properties of 
semisolid cast A356 Al alloy," Materials Science and Technology, vol. 26, pp. 12261231, Oct. 2013.

[10] J.-C. Lee, J.-Y. Byun, S.-B. Park, and H.-I. Lee, "Prediction of Si contents to suppress the formation of Al4C3 in the SiCp/Al composite," Acta Materialia, vol. 46, pp. 1771-1780, Mar. 1998.

[11] K. Morsi and A. Esawi, "Effect of mechanical alloying time and carbon nanotube (CNT) content on the evolution of aluminum (Al)-CNT composite powders," Journal of Materials Science, vol. 42, pp. 4954-4959, July. 2007.

[12] M. Gelbstein, I. Edry, N. Froumin, and N. Frage, "Interfacial Chemical Interactions in the (Alumina/Graphite/Al Alloys) System: Thermodynamic Modeling and Experimental Results," Metallurgical and Materials Transactions A, vol. 40, pp. 932936, Apr. 2009.

[13] J. S. Benjamin and M. J. Bomford, "Dispersion strengthened aluminum made by mechanical alloying," Metallurgical Transactions A, vol. 8, pp. 1301-1305, 1977.

[14] L. Jiang, Z. Li, G. Fan, L. Cao, and D. Zhang, "The use of flake powder metallurgy to produce carbon nanotube (CNT)/aluminum composites with a homogenous CNT distribution," Carbon, vol. 50, pp. 1993-1998, Apr. 2012.

[15] G. Fan, R. Xu, Z. Tan, D. Zhang, and Z. Li, "Development of Flake Powder Metallurgy in Fabricating Metal Matrix Composites: A Review," Acta Metallurgica Sinica (English Letters), vol. 27, pp. 806-815, 2014.

[16] L. Jiang, Z. Li, G. Fan, L. Cao, and D. Zhang, "Strong and ductile carbon nanotube/aluminum bulk nanolaminated composites with two-dimensional alignment of carbon nanotubes," Scripta Materialia, vol. 66, pp. 331-334, Mar. 2012.

[17] Z. Li, L. Jiang, G. Fan, Y. Xu, D. Zhang, Z. Chen, et al., "High volume fraction and uniform dispersion of carbon nanotubes in aluminium powders," Micro \& Nano Letters, vol. 5, pp. 379-381, Dec. 2010.

[18] H. J. Choi, J. H. Shin, and D. H. Bae, "The effect of milling conditions on microstructures and mechanical properties of Al/MWCNT composites," Composites Part A: Applied Science and Manufacturing, vol. 43, pp. 1061-1072, July. 2012.

[19] Z. Y. Liu, S. J. Xu, B. L. Xiao, P. Xue, W. G. Wang, and Z. Y. Ma, "Effect of ballmilling time on mechanical properties of carbon nanotubes reinforced aluminum 
matrix composites," Composites Part A: Applied Science and Manufacturing, vol. 43, pp. 2161-2168, Dec. 2012.

[20] S.-H. Hong, D.-W. Lee, and B.-K. Kim, "Manufacturing of aluminum flake powder from foil scrap by dry ball milling process," Journal of Materials Processing Technology, vol. 100, pp. 105-109, Apr. 2000.

[21] X.-N. Hao, H.-P. Zhang, R.-X. Zheng, Y.-T. Zhang, K. Ameyama, and C.-L. Ma, "Effect of mechanical alloying time and rotation speed on evolution of CNTs/Al-2024 composite powders," Transactions of Nonferrous Metals Society of China, vol. 24, pp. 2380-2386, July. 2014.

[22] L. Lu, M. O. Lai, and C. W. Ng, "Enhanced mechanical properties of an Al based metal matrix composite prepared using mechanical alloying," Materials Science and Engineering: A, vol. 252, pp. 203-211, Sep. 1998.

[23] A. Nieto, A. Bisht, D. Lahiri, C. Zhang, and A. Agarwal, "Graphene reinforced metal and ceramic matrix composites: a review," International Materials Reviews, vol. 62, pp. 241-302, Oct. 2016.

[24] S. F. Bartolucci, J. Paras, M. A. Rafiee, J. Rafiee, S. Lee, D. Kapoor, et al., "Graphene-aluminum nanocomposites," Materials Science and Engineering: A, vol. 528, pp. 7933-7937, Oct. 2011. 